\title{
Monitoring of severe weather events using RGB scheme of INSAT-3D satellite
}

\author{
A K Mitra ${ }^{1, *}$, Shailesh Parihar ${ }^{1}, \mathrm{~S}$ K Peshin ${ }^{1}, \mathrm{R}$ Bhatla ${ }^{2}$ and R S Singh ${ }^{2}$ \\ ${ }^{1}$ India Meteorological Department, New Delhi 110 003, India. \\ ${ }^{2}$ Banaras Hindu University, Varanasi 221 005, India. \\ *Corresponding author.e-mail: ashimmitra@gmail.com
}

MS received 20 September 2017; revised 25 April 2018; accepted 4 May 2018;

published online 1 February 2019

In this study, real-time analysis of products and information dissemination (RAPID), a web-based quick visualisation and analysis tool for INSAT satellite data on a real-time basis has been introduced for identification of pre-monsoon severe weather events. The tool introduces the next generation weather data access and advanced visualisation. The combination of channels using red-green-blue (RGB) composites of INSAT-3D satellite and its physical significant value contents are presented. The solar reflectance and brightness temperatures (BTs) are the major components of the RGB composite. The solar reflectance component of the shortwave thermal infrared (IR) $(1.6 \mu \mathrm{m})$, visible $(0.5 \mu \mathrm{m})$ and thermal IR channels $(10.8 \mu \mathrm{m})$ representing the cloud microstructure is known as Day Microphysics (DMP) RGB and the BT differences between 10.8, 12.0 and $3.9 \mu \mathrm{m}$ is known as Night Microphysics (NMP) RGB. The threshold technique has been developed separately for both the RGB products of the year 2015-2016 and 2016-2017 of March-June, prior to the event (1-3 hr) for the detection of the thunderstorms. A validation analysis was conducted using the Forecast Demonstration Project of Storm Bulletins for pre-monsoon weather systems prepared by the India Meteorological Department and RADAR observations, demonstrating that this approach is extremely useful in recognising the area of convection prior to the occurrence of the events by the RGB thresholds. The validation of these thresholds has been carried out for March-June 2017 . Both the RGBs i.e., DMP and NMP have a reasonable agreement with the ground-based observations and RADAR data. This threshold technique yields a very good probability of thunderstorm detection more than $94 \%$ and $93 \%$ with acceptable false alarm conditions, less than 3\% and 5\% for DMP and NMP, respectively. Furthermore, the limitations of these RGB products are additionally highlighted, and the future extent of refinement of these products in perspective of a rapid scan strategy is proposed. The threshold techniques are found to be useful for nowcasting application and are being used operationally using the RAPID tool.

Keywords. DMP; NMP; RAPID; RGB.

\section{Introduction}

An initial stage of instability is a very essential factor in nowcasting and short-term forecasting. This is basically due to the ascent of large quantities of warm air, lifting forces and surface heating during summer time (Mitra et al. 2012). Generally, in weather forecasting, it is extremely valuable to assess when and where the initialisation of instability is going to occur. For the purpose of forecasting severe weather, it is useful to predict the initial stage when atmospheric instability 
produces significant convection (Showalter 1953; George 1960; Rackliff 1962; Boyden 1963; Chrysoulakis et al. 2003; Science Plan 2005).

The thunderstorm activities start from early March onwards with the advancement of the season in India. The thunderstorm frequency is higher during the pre-monsoon season (March-May) due to the unstable atmosphere of increase in maximum temperatures at surface levels. During the pre-monsoon months (March-May), there are as many as 35-45 days of thunderstorm occurrences over northeast India (Science report 2005) whereas over the northwest India the thunderstorm activity is the highest in the month of March-April, because of associated western disturbances. During the winter and pre-monsoon seasons in India, hail is observed (Das et al. 2014). Nizzamuddin (1993) has reported about 29 hail days per year (analysis of India Meteorological Department (IMD) reports from 1982 to 1989) of moderate-to-severe intensity. Eliot found that out of 597 hailstorms in India, 153 yielded hailstones of 3 -cm diameter or greater.

In the current scenario, the impact of severe weather events particularly thunderstorms over the Indian landmass is high and it has not been studied solely by any means of thresholds criteria using satellite data in each spatial and temporal resolution. With the advancement in the field of remote sensing, it is desirable to utilise its enhanced spatial, spectral and higher temporal resolution for near real-time thunderstorm detection at the regional level of monitoring and nowcasting/forecasting. The INSAT-3D indigenous satellite was launched on 26 July 2013 and provided a new opportunity to the weather forecasters and the user community. It has six-imager channels to provide imaging capability of the earth disc from geostationary altitude in one visible (VIS), and five infrared (IR) channels; shortwave thermal infrared (SWIR), mid-infrared (MIR), water vapour (WV), thermal IR (TIR1) and TIR2 bands. The specification of INSAT-3D imager is given in table 1 . The detailed information of INSAT-3D can be found on http://satellite.imd.gov.in/dynamic/ INSAT3D_Catalog.pdf.

In the present paper, the author initiative concerns to nowcasting, particularly to detect initial stages of instability/convection developments using a new scheme of red-green-blue (RGB) from an INSAT-3D satellite in IMD.

An on-line INSAT-3D visualisation tool and real-time analysis of products and information dissemination (RAPID) have been developed by
Table 1. General specification of INSAT-3D imager.

\begin{tabular}{lcc}
\hline $\begin{array}{l}\text { Spectral } \\
\text { band }\end{array}$ & $\begin{array}{c}\text { Wavelength } \\
(\mu \mathrm{m})\end{array}$ & $\begin{array}{c}\text { Ground } \\
\text { resolution } \\
(\mathrm{km})\end{array}$ \\
\hline VIS & $0.55-0.75$ & 1 \\
SWIR & $1.55-1.70$ & 1 \\
MIR & $3.80-4.00$ & 4 \\
WV & $6.50-7.10$ & 8 \\
TIR1 & $10.3-11.3$ & 4 \\
TIR2 & $11.5-12.5$ & 4 \\
\hline
\end{tabular}

Space Application Center (SAC), India Space Research Organization (ISRO), Ahmedabad, in consultation with IMD and made operational at IMD, New Delhi. The web address is http://rapid. imd.gov.in and shown in figure 1. The RAPID provides features of interest to the scientific community with no specific operating system/software/ library/compiler required on the desktop. It can run on any machine and access through any browser. It has all the features from overlaying map boundaries (World Coastline, State, District Boundaries and Gridlines) to probe the digital INSAT-3D data on the fly in real time. On spot computation of time series, vertical profile, transect, area measurement, distance measurement over the pixel can be done. RAPID is being updated and available to the forecasters/users at every $30 \mathrm{~min}$ from the INSAT-3D satellite.

In the RGB scheme, the cloud types and surface features are identified by different colour shades. The RGB technique was first started by Rosenfeld and Lensky (1998) and Rosenfeld and Woodley (2000) on Advanced Very High Resolution Radiometer data from NOAA satellites. Further, they expanded their work to the precipitationforming processes at night-time using TRMM and MODIS satellites. Several other researchers have utilised the impact of RGB imageries for different weather events. Elmer et al. (2016) have demonstrated the improved interpretation of RGB composites for limb correction of MODIS and VIIRS IR channels. Bell and Molthan (2016) have identified the hail damage to crop vegetation from Aqua MODIS satellite using the RGB imagery. In addition to that, a NASA project (Berndt et al. 2017) filling the gap between research and operational forecasters by introducing new RGB composites of satellite imagery to weather forecasters. Currently, the National Weather Service (NWS) Ocean Prediction Center and NOAA are operationally using the air mass RGB, which highlights differences 


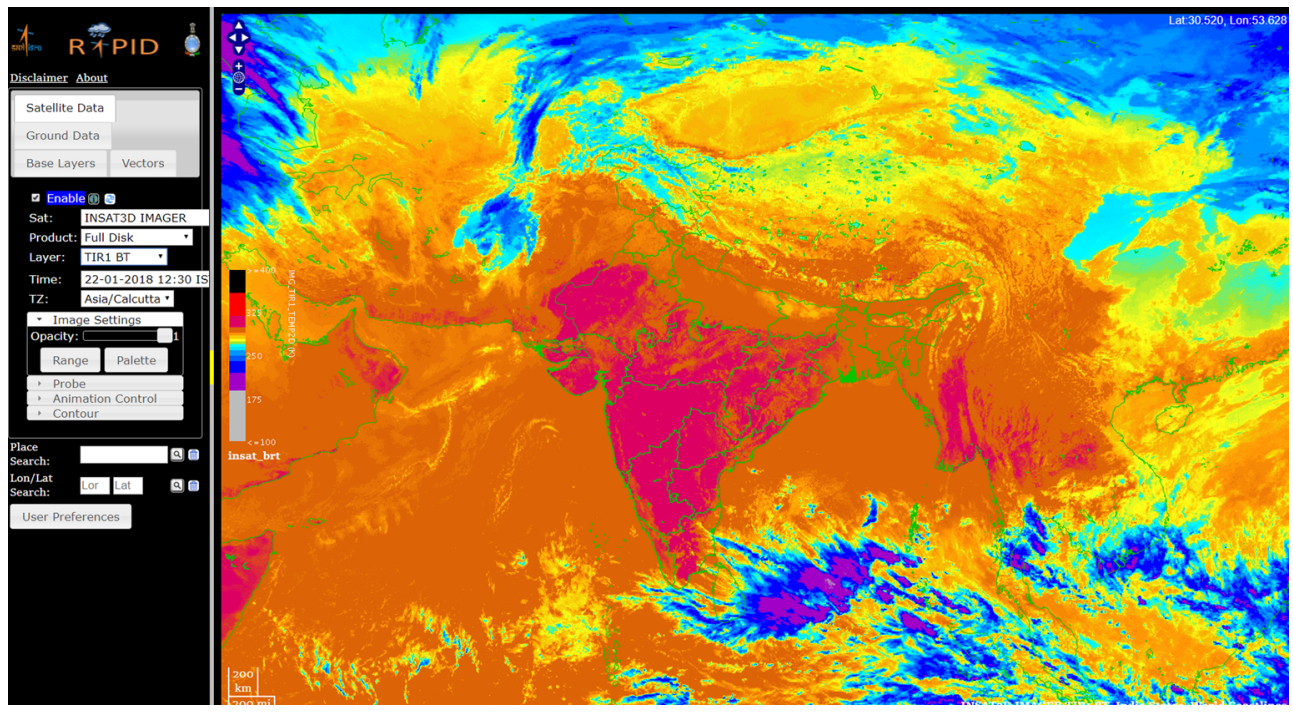

Figure 1. RAPID on IMD website.

between tropical and polar air masses to assist with forecasting strong midlatitude cyclones (Zavodsky et al. 2013; Berndt et al. 2016).

In the current paper, an approach describing a significant part of the physical data content of the INSAT-3D multi-spectral channels satellite utilising RGB composite image for identification of thunderstorms with a threshold technique is attempted. The solar reflectance component of the SWIR $(1.6 \mu \mathrm{m})$, VIS $(0.5 \mu \mathrm{m})$ and TIR channels $(10.8 \mu \mathrm{m})$ representing cloud microstructure is known as Day Microphysics (DMP) RGB and the brightness temperature (BT) differences between 10.8, 12.0 and $3.9 \mu \mathrm{m}$ is known as Night Microphysics (NMP) RGB. The thresholds technique has been developed separately for both the RGB products (2015-2016 and 2016-2017 of MarchJune) for the identification of the thunderstorms. Overall, 250 cases of thunderstorms including hail and squalls with RGB thresholds have been carried out for March-June 2017 against Forecast Demonstration Project (FDP) Storm bulletins of IMD (http://nwp.imd.gov.in/fdp_now/). The FDP Storm bulletins are prepared from the actual observations (including rain gauges, radar observations, etc.) by IMD headquarter at 06:00 and 12:00 UTC from March to June.

\section{Methodology}

\subsection{Formation of RGB microphysics using the INSAT-3D (daytime and night-time)}

Since four decades, the INSAT weather satellites have provided a vital tool for observing all types of weather phenomenon such as monsoon, fog, thunderstorms, tropical convections, etc. India established its own geostationary satellite programme, known as INSAT, in the early 1980s, which has enabled operational forecasters to continuously monitor the development of hazardous weather. Satellite imagery has shown that tropical convection is multi-scalar in nature ranging from isolated cumulus to mesoscale convective systems or mesoscale convective complexes (Tyagi et al. 2012). However, the extract, distil nature of the clouds and its characteristics, and its interpretation for forecasters to understand the weather and utilisation still pose a challenge. The RGB processing offers a unique solution from the different signature of spectral channels into meaningful inference for severe mesoscale phenomena than any individual IR and VIS greyscale images or traditional single-channel colour enhancement techniques. In this paper, Lensky and Rosenfeld (2008) RGB technique (operational in EUMESAT) has been fine tuned according to the INSAT-3D multispectral channels specification and implemented to INSAT Meteorological Data Processing System (IMDPS), IMD, New Delhi. The technique uses a meaningful RGB combination for a qualitative as well as quantitative analysis of the cloud microphysics of INSAT-3D imager channels.

\subsection{Daytime microphysics colour scheme}

Table 2 demonstrates an RGB composition of the DMP colour scheme along with the spectral signature of several cloud types: 0.5, 1.6 and 
$10.8 \mu \mathrm{m}$ in the RGB beams and can be used only in daytime. Figure 2 shows the INSAT-3D RGB composition of DMP imagery of 4 April 2015, 04:00 UTC. In DMP RGB, snow and ice clouds appear red because they strongly absorb in $1.6 \mu \mathrm{m}$; a particle of ice cloud shaded orange (western disturbance) in the imagery whereas the ice cloud with

Table 2. Demonstrates an RGB composition of the DMP colour scheme.

\begin{tabular}{llll}
\hline Beam & \multicolumn{1}{c}{ Channel } & \multicolumn{1}{c}{ Range } & \multicolumn{1}{c}{$\gamma$} \\
\hline Red & VIS $(0.55-0.75 \mu \mathrm{m})$ & $0-100 \%$ & 1.0 \\
Green & SWIR $(1.67 \mu \mathrm{m})$ & $0-60 \%$ & 1.0 \\
Blue & IR $(10.8 \mu \mathrm{m})$ & $203-323 \mathrm{~K}$ & 1.0 \\
\hline
\end{tabular}

large particle (mature cumulonimbus (Cb) cell) identified with the dark red colour. Snow area over the ground appears as full red because its grains are usually larger than cloud ice particles. Lensky and Rosenfeld (2008) and Rosenfeld and Lensky (1998) have very well demonstrated that the ice particles that are formed by the mixedphase process in a supercooled water cloud grow quickly to a much larger size than crystals formed by vapour deposition in ice-only clouds. This helps one to separate convective precipitating clouds from non-precipitating or layer ice clouds. Due to the higher reflectance value in the 1.6 and $0.5 \mu \mathrm{m}$, the desert appears to be bright cyan colour. The $10.8 \mu \mathrm{m}$ BT modulates the blue. Ocean appears to be dark blue because of high thermal

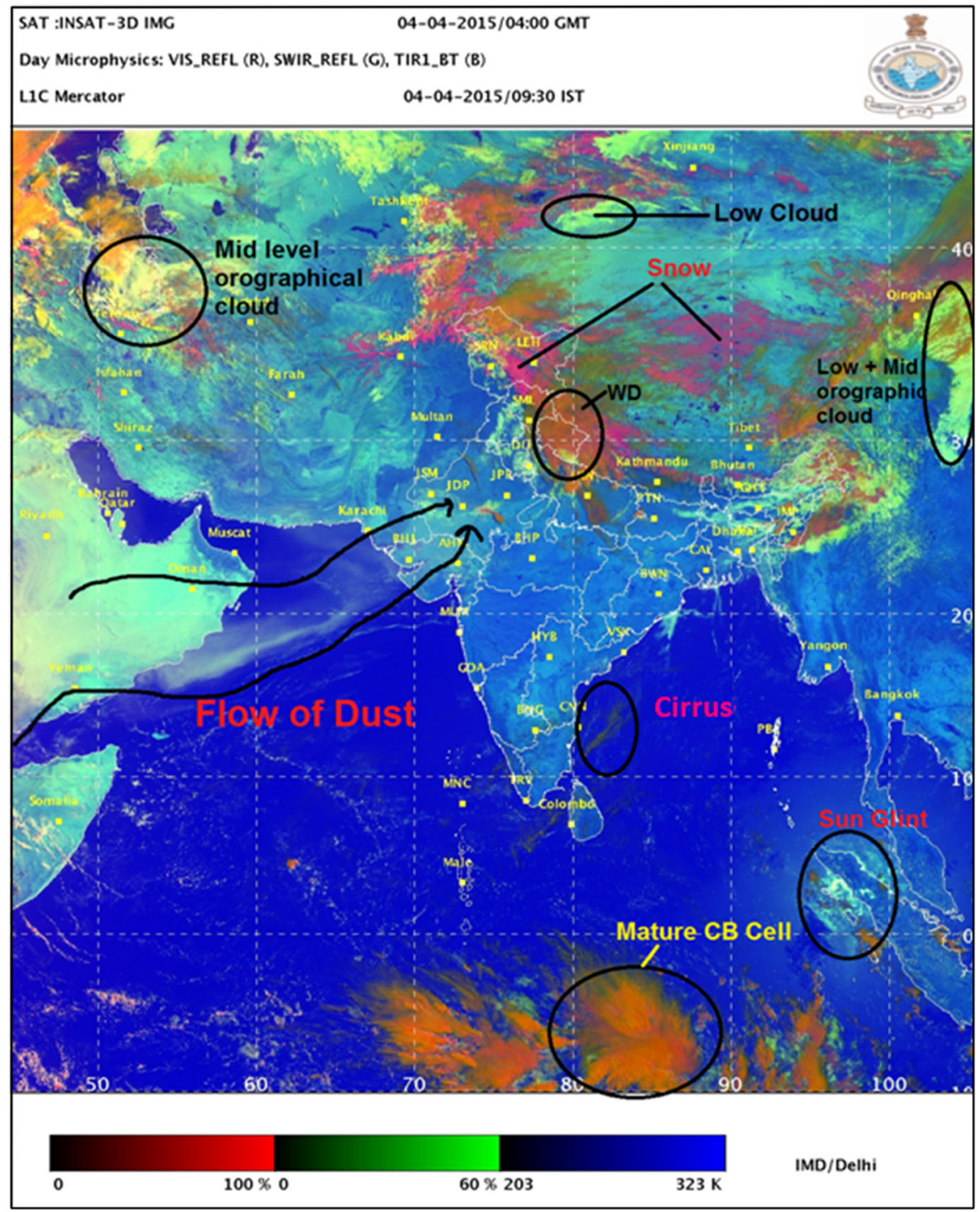

Figure 2. INSAT-3D RGB composition of the DMP colour scheme: $1.6,0.5$, and $10.8 \mu$ m reflectance/temperatures in the red, green and blue beams, respectively, from 4 April 2015, 04:00 UTC. 

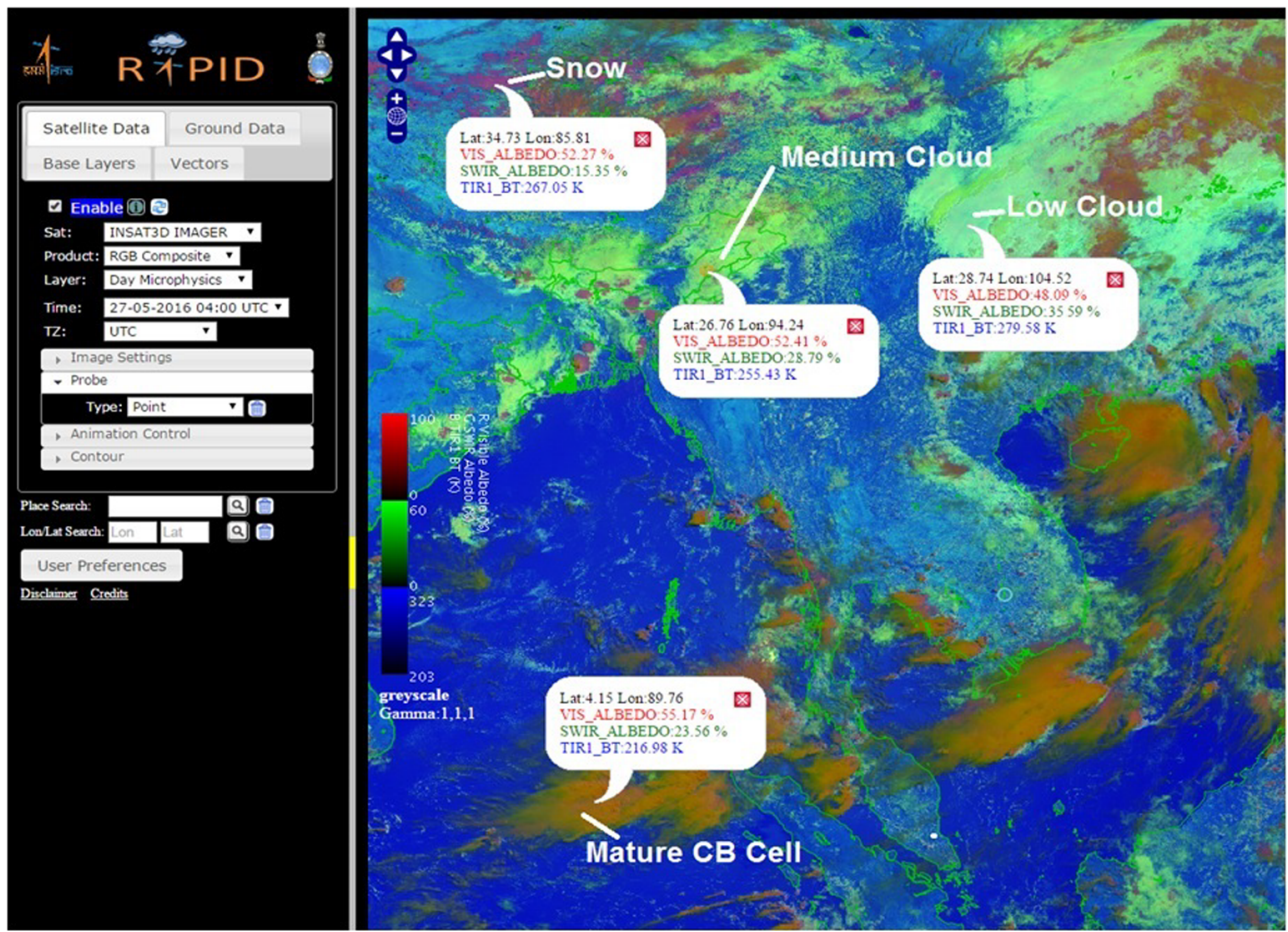

Figure 3. INSAT-3D RGB composition of the DMP colour scheme along with its physical values on 27 May 2016, 04:00 UTC.

emission. The major applications of this colour scheme are an analysis of different cloud types, initial stages of convection, maturing stages of a thunderstorm, identification of snow area and the detection of fires. An ideal case of DMP colours scheme along with its physical values on 27 May 2016, 04:00 UTC is shown by RAPID in figure 3. From this figure, it can be easily demarcated the low/medium/CB clouds and snow. The physical value of VIS albedo for low/medium/CB clouds and snow is almost the same i.e., approximately $50 \%$ but SWIR albedo is different; as in the case of snow is very low compared to low/medium/CB clouds. This is because of strong absorption in $1.6 \mu \mathrm{m}$. For mature $\mathrm{CB}$ cell, the large particle of ice cloud lower the temperature and appears to be less than $220 \mathrm{~K}$ compared to higher temperatures of low/medium/snow (above $250 \mathrm{~K})$.

\subsection{Night-time microphysics colour scheme}

Table 3 demonstrates an RGB composition of the NMP colour scheme along with the spectral signature of several cloud types: BT differences between TIR2-TIR1, TIR1-MIR and TIR1 in the RGB beams and can be used at night-time only. NMP is used to depict the evolution of nighttime clouds/low stratus. It can also be used in the
Table 3. Shows an RGB composition of the NMP colour scheme.

\begin{tabular}{llcc}
\hline Beam & \multicolumn{1}{c}{ Channel } & Range $(\mathrm{K})$ & $\gamma$ \\
\hline Red & IR 12.0-10.0 $\mu \mathrm{m}$ (TIR2-TIR1) & -4 to +2 & 1.0 \\
Green & IR 10.8-3.9 $\mu \mathrm{m}$ (TIR1-MIR) & -4 to +6 & 1.0 \\
Blue & IR 10.8 $\mu \mathrm{m}$ (TIR1) & $243-293$ & 1.0 \\
\hline
\end{tabular}

detection of fires, low-level moisture concentration and cloud classifications. Figure 4 shows the INSAT-3D RGB composition of NMP imagery of 23 April 2014, 21:30 UTC. In NMP RGB, the clouds' opaqueness is being measured by the BT difference between the 12.0 and $10.8 \mu \mathrm{m}$ channels (12.0-10.8) (Inoue 1987) and it is shown in red through the BT contrast in the vicinity of 10.8 and $3.9 \mu \mathrm{m}$ channels (10.8-3.9) modulates the green bar. The BT distinction in these two bands recognises stratus clouds comprising water droplets vs. cirrus clouds and also cloud-free areas. Lensky and Rosenfeld (2003a) demonstrated the importance of BT difference between 10.8 and $3.9 \mu \mathrm{m}$ channels to particle size, and utilised this information to delineate precipitation (Lensky and Rosenfeld 2003b). The large difference between these two channels indicates clouds with small droplets. An ideal case of NMP colours scheme along with its physical values on 14 June 2016, 17:30 UTC is shown by 


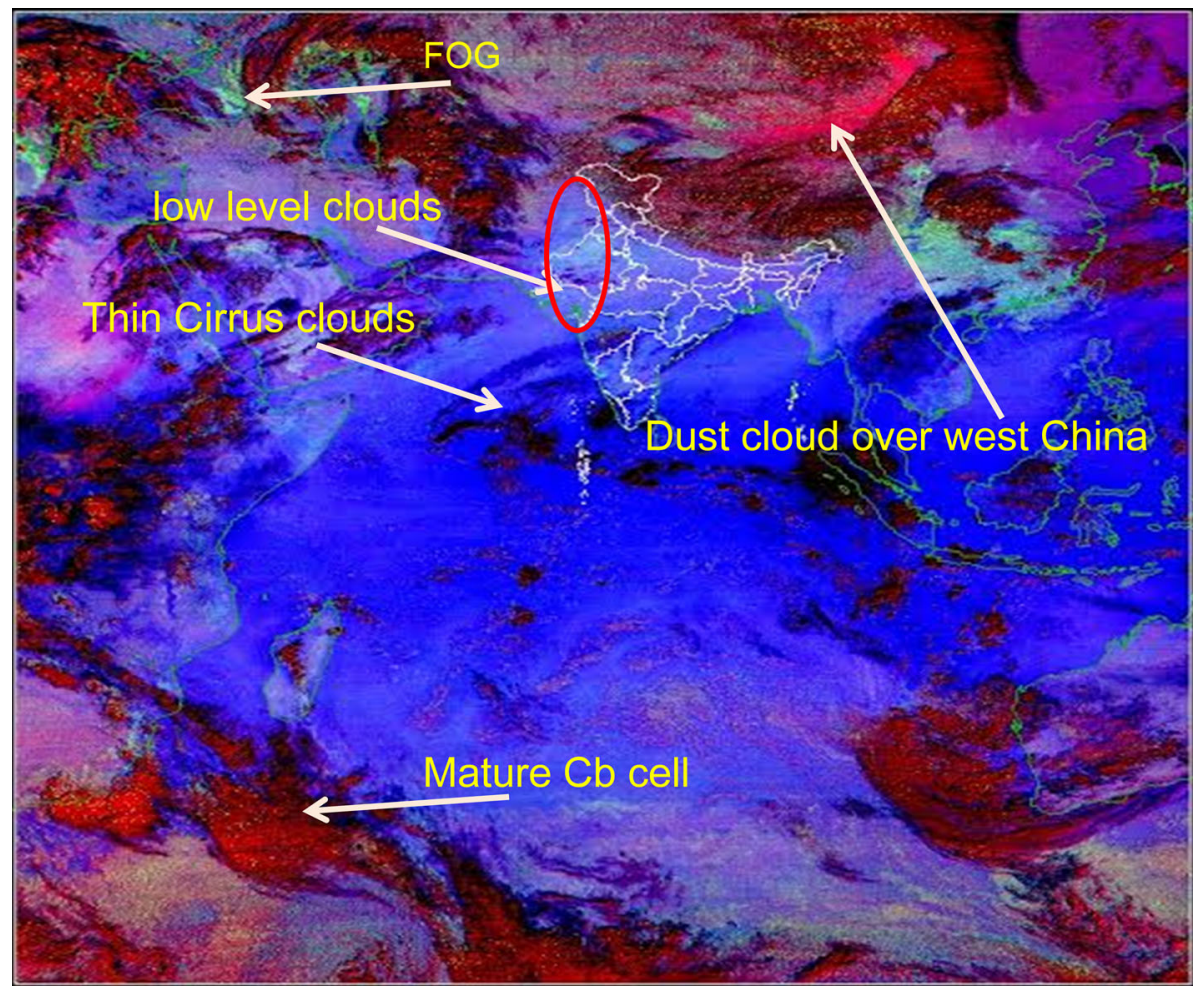

Figure 4. INSAT-3D RGB composition of the NMP colour scheme: 10.8, 12.0 and $3.9 \mu \mathrm{m}$ reflectance/temperatures in the red, green and blue beams, respectively, from 23 April 2014, 21:30 UTC.

RAPID in figure 5. From this figure, it can be easily demarcated the low/medium and CB clouds during night-time. It can be noted that the physical value of different classes, colour schemes and its interpretation of low/medium clouds is different in daytime and night-time microphysics. The tops of cold $\mathrm{Cb}$ radiation emitted from $10.8 \mu \mathrm{m}$ are very low, resulting in low temperature $(<220 \mathrm{~K})$ and showing sprinkled shading at the developed $\mathrm{Cb}$ tops. In this way, the developed $\mathrm{Cb}$ clouds around evening/night-time are seen in sprinkled orangered shading when contrasted with low and medium clouds.

\subsection{Threshold technique for identifying thunderstorm in DMP and NMP prior to $3 \mathrm{hr}$}

The general methodology of thunderstorm detection using the satellite involves identification of some threshold radiance or BT at different wavelengths. The channel TIR2 is the Split-Window IR channel and is centred at approximately $12 \mu \mathrm{m}$ whereas the channel TIR1 is centred at approximately $11 \mu \mathrm{m}$. At these two wavelengths, a different amount of energy is emitted by the optically thin clouds. While the similar amount of energy is emitted by the optically opaque clouds at these wavelengths. Therefore, the regions of thin clouds (high, thin cirrus) can be very well identified by subtracting these two channels. In contrast to TIR, the INSAT-3D MIR channel is sensitive to reflected and emitted thermal energy. This reflected energy relies on the relative points between the sun, clouds, the position of the satellite and reflecting objects, e.g., ocean, land, deserts, snow ground, ice particles and water droplets in clouds. The MIR channel can possibly segregate clouds composed of water particles or ice crystals. In the process, clouds composed of water reflect considerably higher MIR energy than the clouds composed of ice crystals or snow-covered area. The measure of reflection is dependent upon the span of the water drops and ice particles. During the night, reflection is not adding to the estimations and any contrasts among water and ice/snow are purely based on emission.

The INSAT-3D RGB microphysics scheme is extremely valuable to the extent cloud analysis, mesoscale convections are concerned. In this scheme, in view of the low reflectance at $3.9 \mu \mathrm{m}$ channel (Lensky and Rosenfeld 2003a), water clouds are shaded in white and generally they do not precipitate because these cloud drops are small in size whereas clouds with larger drops are 


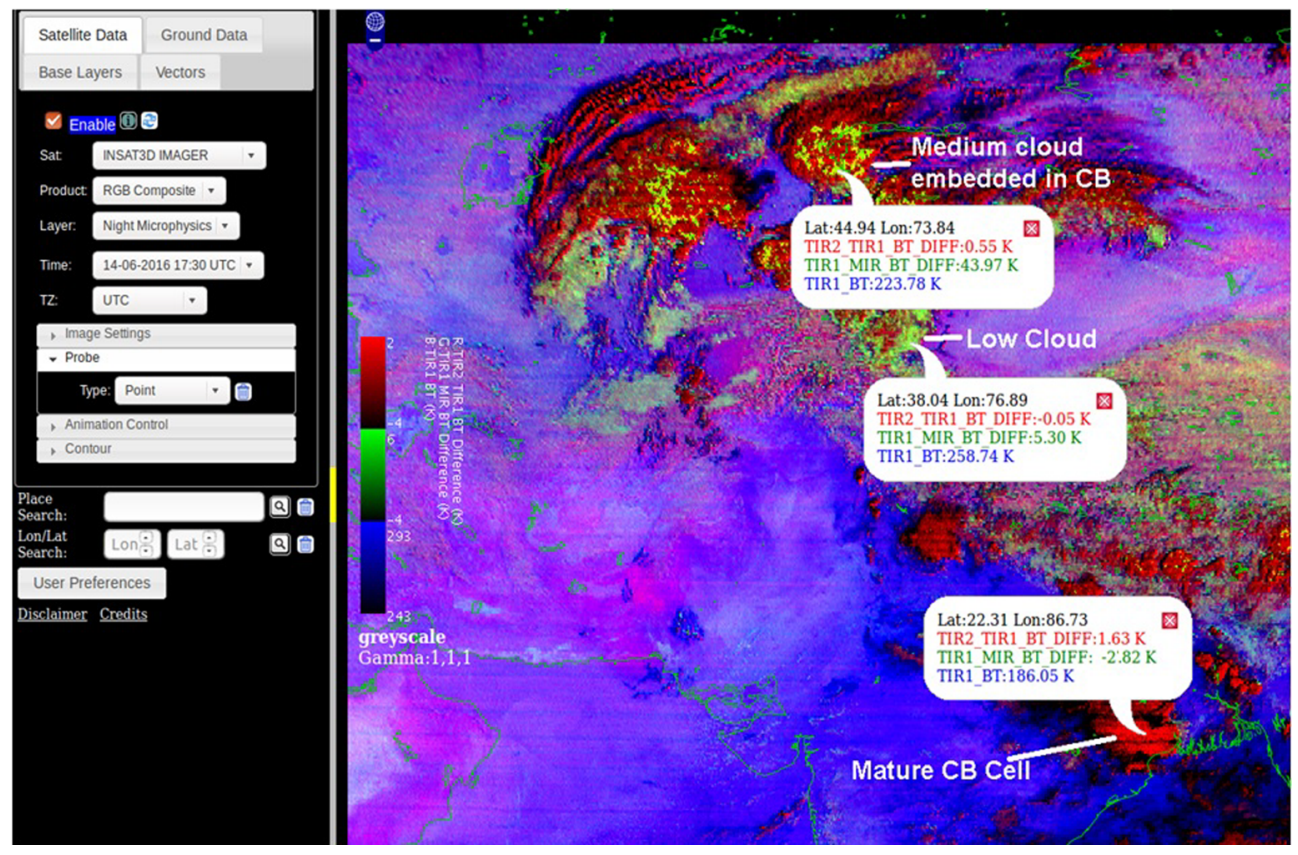

Figure 5. INSAT-3D RGB composition of the NMP colour scheme along with its physical values on 14 June 2016, 17:30 UTC.

shaded pink and produce significant rain. Hence, the supercooled water clouds seem to be in pink shading due to the lower temperature. Cold and thick clouds with large ice particles, e.g., Cb tops, shaded brown. In order to determine the thresholds criteria for identification of thunderstorms in RGBs of DMP and NMP images, the composition of channels along with its physical values has been studied extensively and analysed from 2 years (2015-2016 and 2016-2017) of March-June data. The thunderstorms case including hails and squalls using RGB thresholds has been validated against FDP Storm Bulletins of IMD. The DMP and NMP thresholds along with its resolution and time of use for thunderstorm identification prior to the event (1-3 hr) have been listed in table 4 . However, it can be noticed from table 4 that ranges of constraint conditions are overlapping between 'Thunderstorm with rain' and 'Thunderstorm with hail'. This is due to the facts of the hail conditions which are mainly monitored from the shape of clouds, cloud thickness, electrical activity inside the cloud, precipitation levels. In addition to that, the internal energy of hailstorm formation is very complex, and a strong updraft plays an important role in energy variations (Wang et al. 2018). Generally, a strong updraft carries hydrometeors to the melting level; the majority of particles merge with growing ice crystals. When the quantity and size of ice crystals increase to certain thresholds (Kolarič 2013), hail eventually forms. From the geostationary satellite, with a given spectral resolution, it is very difficult to distinguish the hails within thundery clouds accurately. In this paper, we verified our thresholds with radar and actual observation reported by the stations.

\section{Results and discussion}

The occurrence of thunderstorms reported by IMD observations of FDP STORM bulletin is analysed with RGB products, i.e., DMP and NMP, based on the threshold criteria given in table 4. Overall 16 cases of the thunderstorms have been considered in their most intense phases throughout the pre-monsoon season and shown in table 5. On an average, the entire time period of an intense thunderstorm was $15 \mathrm{~min}$ to $1 \mathrm{hr}$. It is essential to specify that, in this study, before the thunderstorm events imply the time, convection appearance was not seen in the satellite imageries to the particular station. Once the convection starts, in the RGB features, the initial hours are critical to recognise the location and expanding the cautioning lead times. Traditionally, the satellite instruments only observe the highest cloud tops, blocking the internal structure of the storm (Setvak et al. 2008, 2010). Considering the advantages of the high temporal sampling of the INSAT-3D satellite and 
Table 4. DMP and NMP thresholds along with its pixel resolution and time of use for thunderstorms prior to the event $(1-3 \mathrm{hr})$.

\begin{tabular}{|c|c|c|c|c|}
\hline Product & $\begin{array}{c}\text { Pixel } \\
\text { resolution } \\
(\mathrm{km})\end{array}$ & Time & Source & Use (conditions) \\
\hline $\begin{array}{l}\text { Night-time RGB } \\
(3.9,10.8 \mu \mathrm{m})\end{array}$ & $1-4$ & $\begin{array}{l}\text { 13:00 to 02:00 UTC } \\
\text { (of next day) } \\
\text { Half hourly }\end{array}$ & $\begin{array}{l}\text { RAPID } \\
\text { rapid.imd.gov.in }\end{array}$ & $\begin{array}{l}\text { 1. TIR2-TIR1 BT DIFF }>\text { must be } \\
\text { negative and }-4 \text { to } 1.5 \mathrm{~K} \\
\text { 2. TIR1-MIR BT must be }-26 \mathrm{~K} \text { to } \\
\text { - } 1 \text {, if positive }=\text { ice/snow clouds } \\
\text { 3. TIR1 BT }<255 \mathrm{~K} \\
\longrightarrow \text { Thunderstorm with rain } \\
\text { (i) TIR2-TIR1 BT DIFF }>\text { becoming } \\
\text { positive and }-2 \text { to } 2 \mathrm{~K} \\
\text { (ii) TIR1-MIR BT must be }-26 \mathrm{~K} \\
\text { to } 25 \\
\text { (iii) TIR } 1 \text { BT }<250 \mathrm{~K} \\
\longrightarrow \text { Thunderstorm with hail }\end{array}$ \\
\hline $\begin{array}{l}\text { Daytime RGB } \\
\text { (TIR, SWIR, VIS) }\end{array}$ & $1-4$ & $\begin{array}{l}\text { 02:30 to } 12: 30 \text { UTC } \\
\text { Half hourly }\end{array}$ & $\begin{array}{l}\text { RAPID } \\
\text { rapid.imd.gov.in }\end{array}$ & $\begin{array}{l}\text { (i) TIR1 BT rate of change is (in } \\
\text { consecutive hours) }-5 \text { to }-15 \mathrm{~K} \\
\text { (ii) VIS } 26-55 \% \text { (increasing trend) } \\
\text { (iii) SWIR }<28 \% \text { (decreasing trend) and } \\
\text { (iv) VIS }>\text { SWIR } \\
\longrightarrow \text { Thunderstorm with rain } \\
\text { (i) TIR } 1 \text { BT rate of change (in } \\
\text { consecutive hours) is }-5 \text { to }-38 \mathrm{~K} \\
\text { (ii) VIS } 18-58 \% \text { (increasing trend) } \\
\text { (iii) SWIR }<25 \% \text { (decreasing trend) and } \\
\text { (iv) VIS }>\text { SWIR } \\
\longrightarrow \text { Thunderstorm with hail }\end{array}$ \\
\hline
\end{tabular}

its multi-spectral channels capability, the given threshold criteria in table 4 may be taken as a measure of convective activity.

Figure $6(\mathrm{a}$ and $\mathrm{b})$ illustrates all the 16 cases of the thunderstorms as shown in table 5, from initiation to dissipation stages for different cities all over the country. The red line depicted within the figures indicating the actual time of thunderstorm occurrence. The initiation and developing phases of a thunderstorm are clearly ascertained when analysed using the proposed RGB approach. In the daytime, DMP, the VIS and SWIR pixel values were showing the opposite trend, i.e., higher value of VIS albedo (VIS $>$ SWIR, by 70-80\%) than SWIR and the rate of change in the TIR1 pixel in the consecutive hours, represents the stronger convective activity. During the occurrence of maximum convection, the value of each parametric quantity of RGB provides good indicators for differences in intensity from one case to the other. In the night-time, NMP, figure 6(b), the BT difference between TIR1 and MIR, plays the major role in identifying the area of location of convective activities along with TIR 1 temperature. Differencing the MIR information from the TIR produces negative values for clouds composed of water droplets and almost zero or positive values for ice/snow particles. The positive values of TIR-MIR determine the availability of hydrometeors within the clouds and merge with growing ice crystals that eventually result in the hailstorm. However, the accuracy of the hailstorm from satellite observation may be the issue due to the proper verification from the ground station as most of the time it goes unnoticed. The only way is to validate through weather radar as it is widely used to observe hailstorms.

It can be interpreted from table 5 and figure 6 (a and $\mathrm{b})$ that the thresholds technique performed very well for all the 16 cases for the detection of the thunderstorms prior to the event (1-3 hr) and its life cycle including daytime and night-time. The combined analysis of TIR2-TIR1, TIR1-MIR and TIR1 data indicates a noticeable contrast 


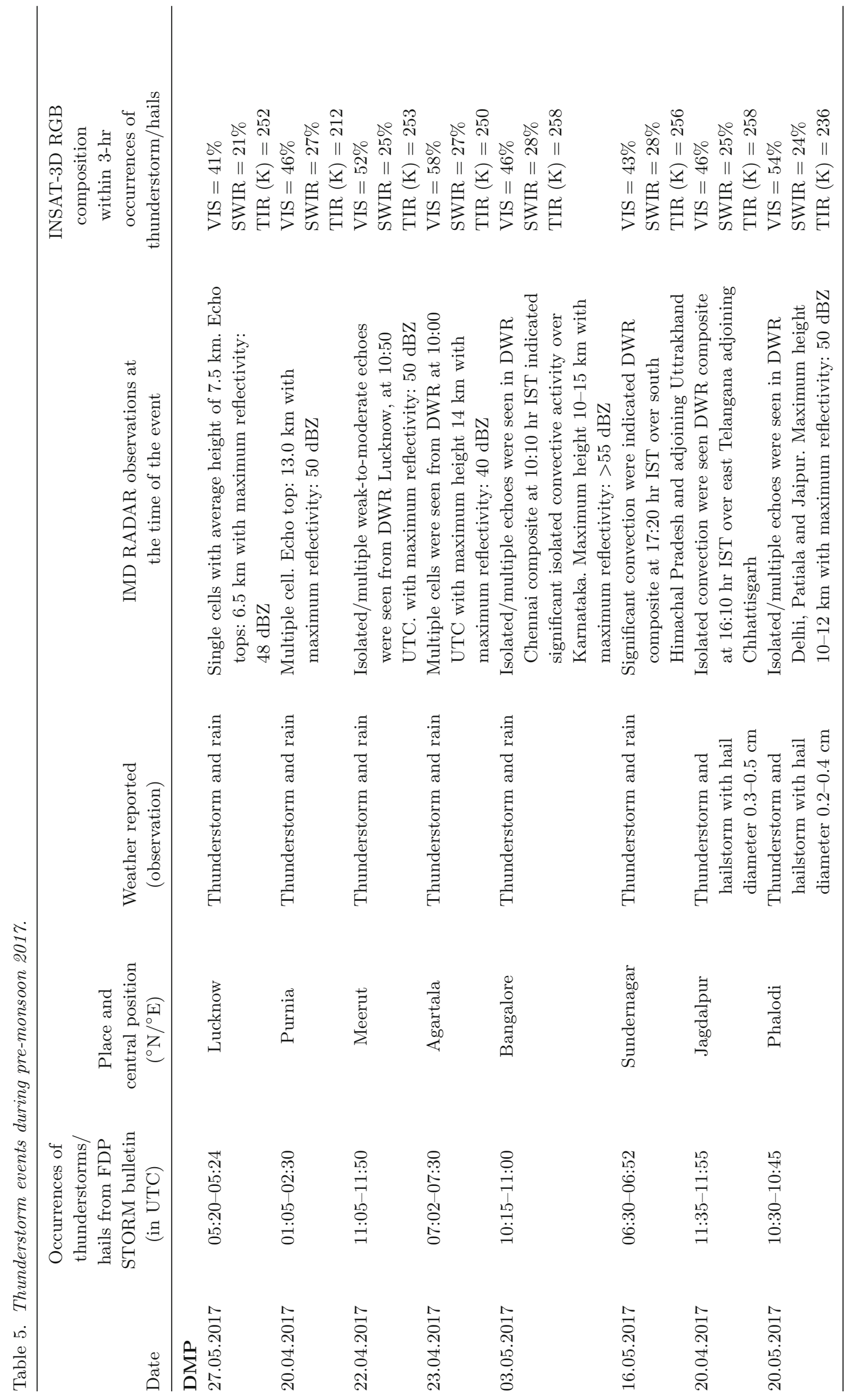




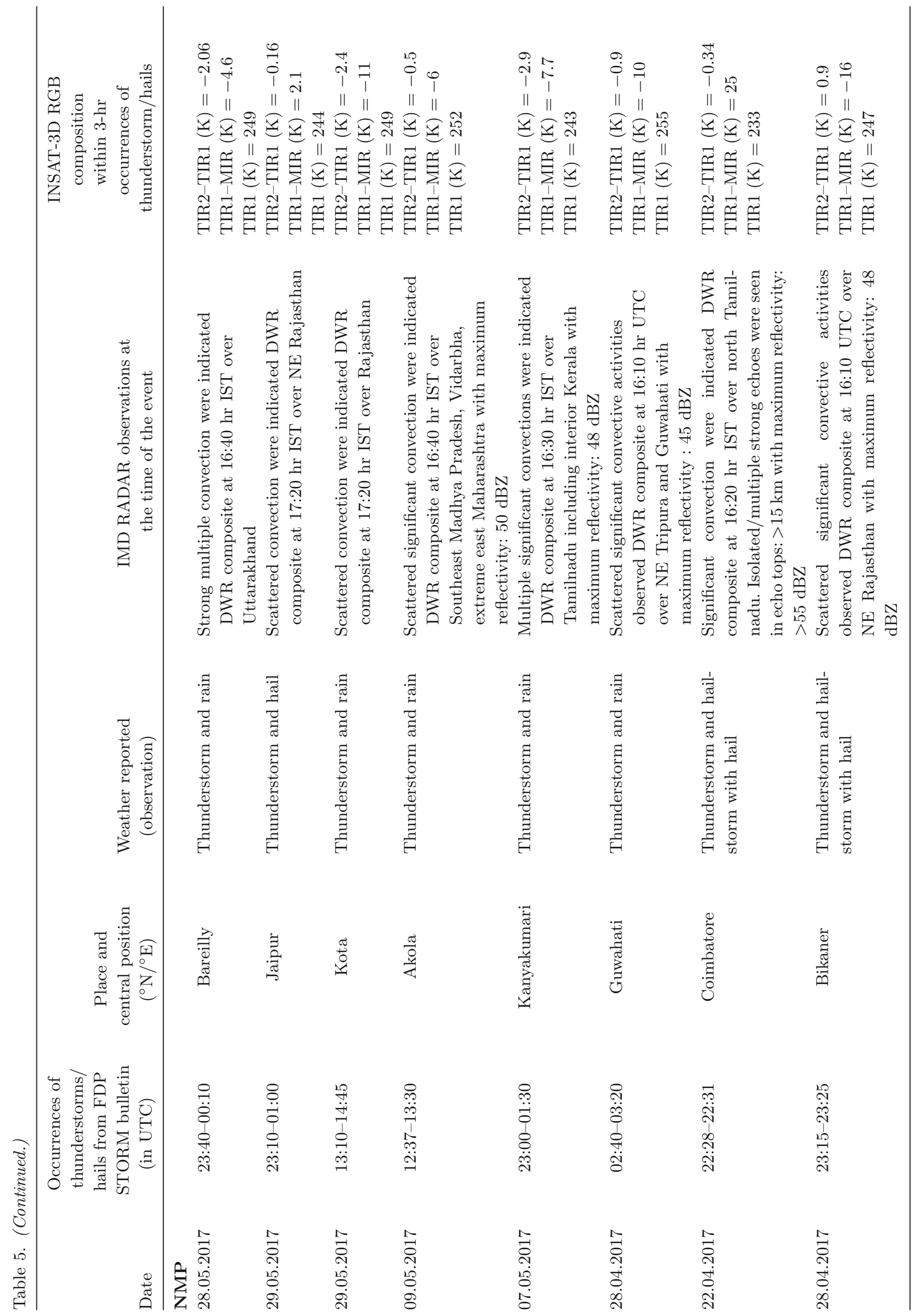




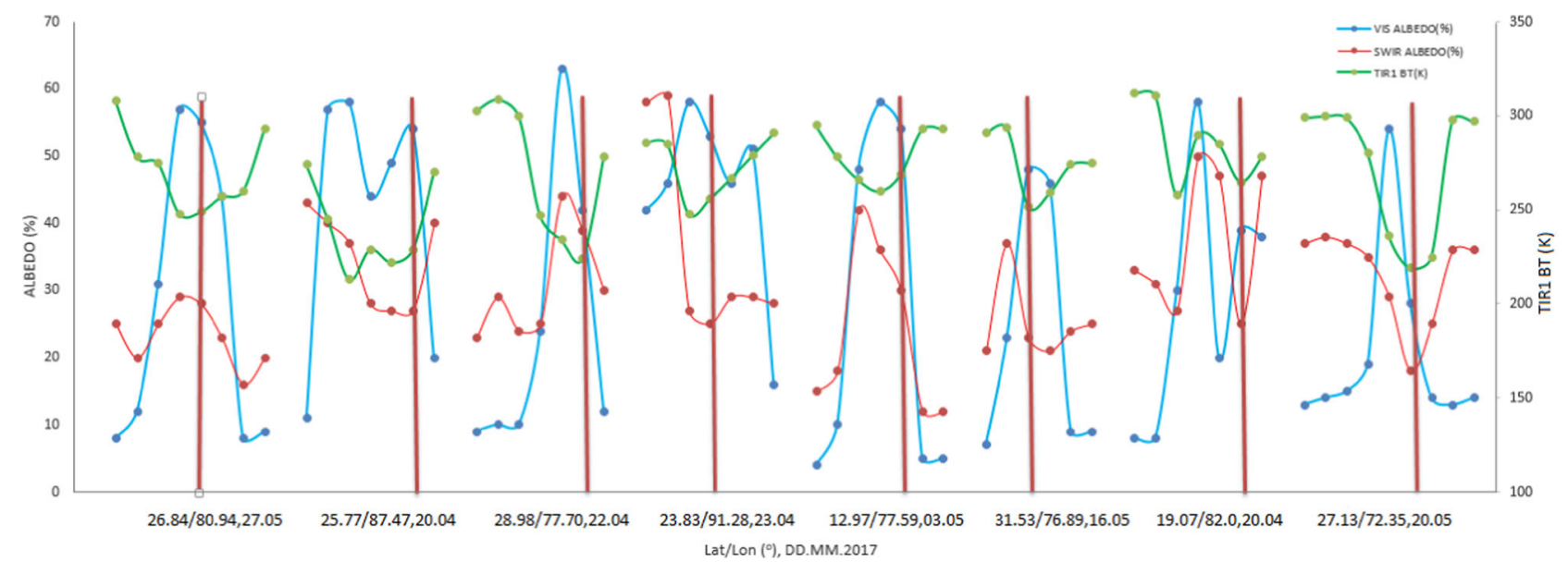

(a) DMP

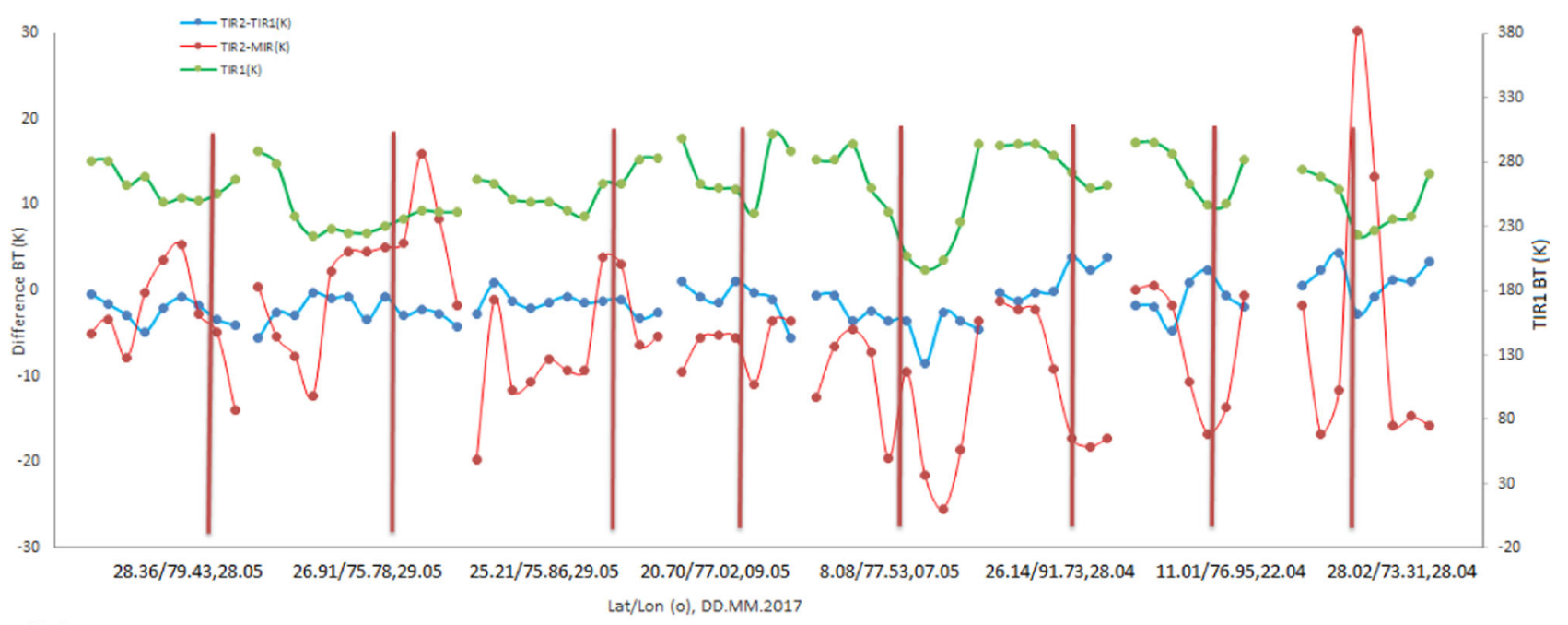

(b) NMP

Figure 6. (a and b) All the 16 cases of thunderstorms from initiation to dissipation stage.

in extreme and less severe cases. This routine analysis of RGB parameters could be vital to the field forecasters and can be used as a nowcast tool for the subsequent few hours of the thunderstorms.

\subsection{Validation with actual observations and radar data}

Figure 7 shows the comparison between radar and NMP RGB satellite imageries of 23 May 2017. It can be seen from the Kolkata DWR composite image at 11:21 UTC indicating strong convection over east and northeast Jharkhand adjoining West Bengal. This was squall line echo (Max dBZ 55-60 and height $>15 \mathrm{~km}$ ) reported by DWR Kolkata. From the RAPID, the RGB imagery demonstrating the significant convective clouds over the same area and the maximum radar reflectivity is also observed near the NMP pixels. The NMP parameters at 12:30 UTC were TIR2-TIR1 $(\mathrm{K})=$ -1.26 ; TIR2-MIR $(\mathrm{K})=-12.3$; TIR1 $(\mathrm{K})=$ 249 , meeting the thresholds criteria of a severe thunderstorm. The associated convective clouds in the NMP images have suggested the occurrence of a thunderstorm over Kolkata and accordingly warnings were issued by the IMDs FDP STORM bulletin of 23 May 2017 (FDP STORM Bulletin No. 79 (23 May 2017)), and subsequently, IMD Kolkata Office has issued the Nowcast Bulletin. This event was very well forecasted. The thunderstorm was reported at between 14:30 to 15:00 UTC. Multiple cells are shown by radar which transformed into big cells with a maximum reflectivity of $58.5 \mathrm{dBz}$ with height $>18 \mathrm{~km}$. 

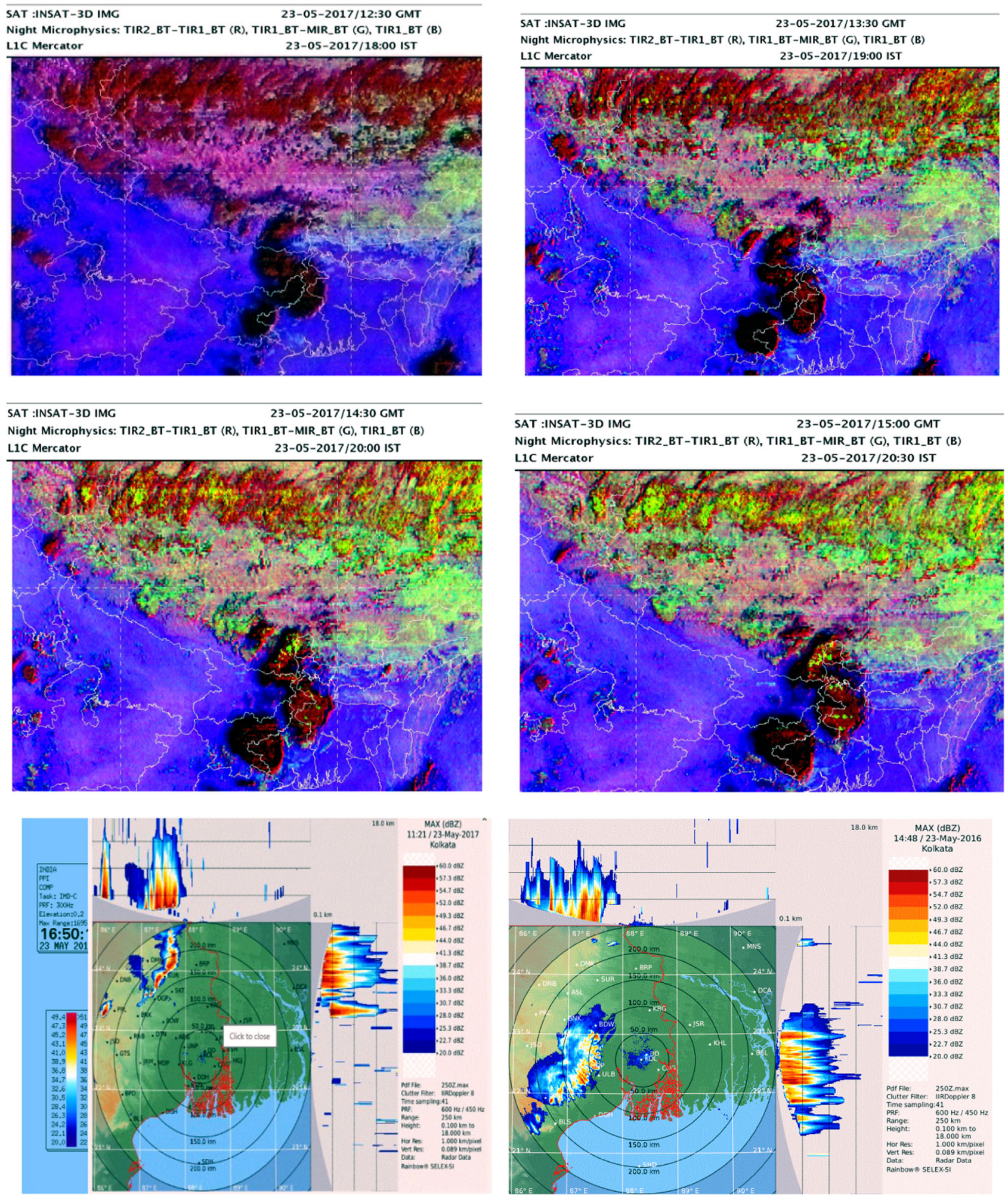

Figure 7. Night-time RGB and radar reflectivity (dBZ) for 23 May 2017.

Both, the INSAT-3D RGB and radar observation, were found to be in good agreement in terms of delineating areas of deep convection. This exercise suggests that thunderstorm events can be more effectively analysed by the INSAT-3D RGB technique at every half an hour interval, with the maximum zone of reflectivity by the radar observation.

A quantitative validation of RGB threshold technique has been carried out for both, DMP 
Table 6. Statistics of DMP and NMP observed using threshold criteria.

\begin{tabular}{lrr}
\hline & DMP & NMP \\
\hline Total no. of observations & 116 & 134 \\
Number of miss (\%) & 3 & 5 \\
No. of hits (\%) & 97 & 95 \\
Per cent of detection (POD) (\%) & 94 & 93 \\
Per cent of false detection (due & 7 & 9 \\
$\quad$ to navigation) (\%) & & \\
Critical success index (\%) & 90 & 87 \\
\hline
\end{tabular}

and NMP, products before the event (1-3 hr) with actual observations and shown in table 6 . The radar data was used to assess the convection evolution. It can be seen that the occurrences of convective activity were identified very well by both the RGB schemes. From table 6 , the per cent of detection using the DMP threshold is 94\%, whereas the NMP threshold is $93 \%$. The false detections are $7 \%$ and $9 \%$, for DMP and NMP, respectively. This may be due to many factors such as high viewing angle scan during early morning and late evening. Over the hilly region such as Sub-Himalayan West Bengal, Western Ghats, Nilgiris in southern parts of the country where surface heating has rapidly intensified. Hence, the localised factor plays an important role along with synoptic forcing for any convection formation. The navigation of the satellite image may also add some false alarms.

However, the INSAT-3D RGB schemes provide necessary precursors for the study of convective formations specifically for severe weather such as thunderstorm and their growth prior to the event. The synoptic information would not provide the internal structure for the study of different life stages and intensity in the development of mesoscale convection during the pre-monsoon season. Even though the lead time of detection of severe weather is very low, the RGB scheme has provided vital information with regard to the development of mesoscale convection over the region and demonstrated very well for nowcasting of mesoscale convection from half-hourly observations from the INSAT-3D RGB.

\subsection{Limitations of these $R G B$ products and future scope}

At present at IMDPS, the DMP and NMP scheme is applied only on imager. In DMP, water and ice clouds, which are more sensitive to the different cloud microstructures, sometimes are not capturing the valuable information of cloud top temperature and resulting in poor understanding of thin clouds. In the orographic region, the development of $\mathrm{CB}$ cell also sometimes gives rise to false alarm because of rising air motion originating at a high level (can be called orographic wave clouds) from the surface and misleading in the NMP. The Lensky and Rosenfeld (2003a) technique is basically applied on rich spectral information of spinning enhanced VIS and infrared imager (SEVIRI) on board METEOSAT Second Generation (MSG, 11 bands spectral information) the European geostationary satellite operated by EUMETSAT, which has the multispectral capability for cloud microphysical characterisation and aerosol-cloud detection. In the current INSAT-3D channels, we have used only six-band spectral information imager. Therefore, the large reflectance of the $\mathrm{Cb}$ and lower level clouds is sometimes not detectable because of unavailability of 0.8 and $1.6 \mu \mathrm{m}$ in the DMP colour scheme. The large negative difference between the 1.6 and $0.6 \mu \mathrm{m}$ represents ice clouds and a large positive difference between the 1.6 and $0.6 \mu \mathrm{m}$ is typical for the surface. An additional missing channel in the INSAT-3D satellite may be a 8 . 7- $\mu \mathrm{m}$ channel, which is sensitive to cloud size distribution, particularly to the particle effective radius. This particular channel can also be used in the sand and dust discrimination. The RGB scheme also has some limitations during dawn-to-dusk period. The work is also going on to apply the DMP and NMP colour scheme over the 19 channels of INSAT-3D Sounder and thereafter newly launched INSAT-3DR satellite, so that staggering of both the satellites will give us every $15 \mathrm{~min}$ of weather events over the Indian region.

To improve the forecasting accuracy for the detection of severe weather and deep convection phenomena, a more adaptable and capable observing technique is required. A rapid scan strategy is required during the pre-monsoon season over the Indian region. Purdom (1996a, b) and Levizzani and Setvák (1996) have demonstrated the use of rapid scan imagery (5 min interval) from GOES-8 for the study of explosive convection and its impact on $30 \mathrm{~s}$ repetition time for the analysis of storm genesis and advancement of squall lines with their fine structure. In view of that, a successful test of a rapid scan using the INSAT-3DR satellite at every 5 -min interval has been conducted over the Indian region at IMDPS, New Delhi, by SAC and IMD. Soon this may be implemented. 


\section{Conclusions}

The availability of multispectral imager channels in INSAT-3D satellite from its predecessor provides us with a new way to look at weather events such as different types of clouds and their microphysics. The most effective way to utilise these products is the use of RGB combinations, such as DMP and NMP, in the RAPID tool for observing different weather phenomena. In this study, we have presented the daytime and night-time RGB scheme using the RAPID visualisation tool for INSAT-3D satellite data on a real-time basis for identification of pre-monsoon severe weather events. The solar reflectance and BTs are the most important elements in the making of the RGB composites. The threshold techniques have been developed separately for both the RGB products of the year 20152016 and 2016-2017 of March-June of data for the detection of the thunderstorms prior to the event (1-3 hr). Both the RGBs, i.e., DMP and NMP, have reasonable agreement with ground-based observations and RADAR data. This threshold technique yields a very good probability of thunderstorm detection more than $94 \%$ and $93 \%$ with acceptable false alarm conditions less than $7 \%$ and $9 \%$ for DMP and NMP, respectively. The threshold's techniques are found to be very useful for nowcasting applications and being used by forecasters and user community operationally using the RAPID tool.

\section{Acknowledgements}

Authors are very much grateful to SAC, Ahmedabad team, for their technical, software expertise and implementation of 'RAPID' tool at IMDPS, New Delhi. We specially thank Shri Ghansyam Sanger and Nitesh Kausik, scientists of SAC for consulting with IMD and their valuable suggestions while developing 'RAPID'. The first author thanks I M Lensky and D Rosenfeld for CAPSAT tool information. The first author greatly appreciated Mr Bikram Sen and Mr Pradeep Sharma from NWFC for timely preparation of FDP STORM bulletins.

\section{References}

Bell J R and Molthan A L 2016 Evaluation of approaches to identifying hail damage to crop vegetation using satellite imagery; J. Oper. Meteor. 4(11) 142-159, https://doi. org/10.15191/nwajom.2016.0411.
Berndt E B, Zavodsky B T and Folmer M J 2016 Development and application of atmospheric infrared sounder ozone retrieval products for operational meteorology; IEEE Trans. Geosci. Remote Sens. 54(2) 958-967, https://doi.org/10.1109/TGRS.2015.2471259.

Berndt E, Molthan A, Vaughan W W and Fuell K 2017 Transforming satellite data into weather forecasts; EOS 98, https://doi.org/10.1029/2017EO064449.

Boyden C J 1963 A simple instability index for use as a synoptic parameter; Meteorol. Mag. 92 198- 210.

Chrysoulakis N, Spiliotopoulos M, Domenikiotis C and Dalezios N 2003 Towards monitoring of regional atmospheric instability through MODIS/AQUA images; In: Proceedings of the International Symposium, Volos, Greece, pp. 7-9.

Das S, Mohanty U C, Tyagi A, Sikka D R, Joseph P V, Rathore L S, Habib A, Baidya S, Sonam K and Sarkar A 2014 The SAARC STORM: A coordinated field experiment on severe thunderstorm observations and regional modeling over the south Asian region; Bull. Am. Meteorol. Soc. 95 603-617.

Elmer N J, Berndt E and Jedlovec G J 2016 Limb correction of MODIS and VIIRS infrared channels for the improved interpretation of RGB composites; J. Atmos. Ocean. Technol. 33(5) 1073-1087.

George J J 1960 Weather forecasting for aeronautics; Academic Press, New York, pp. 409-415.

Inoue T 1987 An instantaneous delineation of convective rainfall areas using split window data of NOAA-7 AVHRR; J. Meteor. Soc. Japan 65 469-481.

Kolarič D 2013 Hail detection methods using radar data; Faculty of Mathematics and Physics, University of Ljubliana.

Lensky I M and Rosenfeld D 2003a Satellite-based insights into precipitation formation processes in continental and maritime convective clouds at night-time; J. Appl. Meteor. 42 1227-1233.

Lensky I M and Rosenfeld D 2003b A night rain delineation algorithm for infrared satellite data based on microphysical considerations; J. Appl. Meteor. 421218 1226 .

Lensky I M and Rosenfeld D 2008 Clouds-aerosolsprecipitation satellite analysis tool (CAPSAT); Atmos. Chem. Phys. 8 6739-6753.

Levizzani V and Setvák M 1996 Multispectral, highresolution satellite observations of plumes on top of convective storms; J. Atmos. Sci. 53(3) 361369 .

Mitra A K, Sharma A K, Bajpai I and Kundu P K 2012 An atmospheric instability derived with MODIS profile using real-time direct broadcast data over the Indian region; Nat. Hazards 63(2) 1007-1023.

Nizzamuddin S 1993 Hail occurrences in India; Weather 48(3) 90-92, https://doi.org/10.1002/j.1477-8696.1993. tb05847.x

Purdom J F W 1996a One minute interval imaging of atmospheric phenomena using NOAA's new generation of geostationary satellites; Preprints, Eighth conference on satellite meteorology and oceanography, AMS, pp. $164-167$.

Purdom J F W 1996b Advanced atmospheric studies using GOES-8/9 multichannel imagery; Proceedings of 
1996 meteorological satellite data users' conference, EUMETSAT EUM P, Vol. 19, pp. 77-86.

Rackliff P G 1962 Application of an instability index to regional forecasting; Meteor. Mag. 91 113-120.

Rosenfeld D and Lensky I M 1998 Satellite-based insights into precipitation formation processes in continental and maritime convective clouds; Bull. Am. Meteor. Soc. $\mathbf{7 9}$ 2457-2476.

Rosenfeld D and Woodley W L 2000 Deep convective clouds with sustained supercooled liquid water down to $-37.5^{\circ} \mathrm{C}$; Nature 405 440-442, https://doi.org/10.1038/35013030.

Science Plan 2005 Severe thunderstorms observations and regional modeling (STORM) programme; Department of Science and Technology, Govt. of India.

Showalter A K 1953 A stability index for thunderstorm forecasting; Bull. Am. Meteor. Soc. 34 250-252.

Setvak M, Lindsey D T, Rabin R M, Wang P K and Demeterova A 2008 Indication of water vapor transport into the lower stratosphere above midlatitude convective storms: Meteosat Second Generation satellite observations and radiative transfer model simulations; Atmos. Res. 89 170-180.

Setvak M, Lindsey D T, Novak P, Wang P K, Radová M, Kerkmann J, Grasso L, Su S-H, Rabin R M, Št'ástka J and Charvát Z 2010 Satellite-observed cold-ring-shaped features atop deep convective clouds; Atmos. Res. 9780 96, https://doi.org/10.1016/j.atmosres.2010.03.009.

Tyagi A, Sikka D R, Suman G and Bhowmik M 2012 A satellite based study of pre-monsoon thunderstorms (Nor'westers) over eastern India and their organization into mesoscale convective complexes; Mausam 63(1) 2954.

Wang P, Shi J, Hou J and Hu Y 2018 The identification of hail storms in the early stage using time series analysis; J. Geophys. Res. 123, https://doi.org/10.1002/ 2017JD027449.

Zavodsky B T, Molthan A L and Folmer M J 2013 Multispectral imagery for detecting stratospheric air intrusions associated with mid-latitude cyclones; J. Oper. Meteorol. 1(7) 71-83.

Corresponding editor: Prashant K SRIVAstava 